\title{
AN INBORN DEFECT OF INTESTINAL ABSORPTION OF CERTAIN MONOSACCHARIDES
}

\author{
BY \\ CHARLOTTE M. ANDERSON, K. R. KERRY,* and R. R. W. TOWNLEY \\ From the Gastroenterological Research Unit, Royal Children's Hospital Research Foundation, \\ Melbourne, Australia
}

(RECEIVED FOR PUBLICATION AUGUST 17, 1964)

Since 1958 defective digestion of the disaccharide sugars has received increasing attention and hereditary congenital deficiencies of the enzymes, lactase, sucrase, and isomaltase, have been very convincingly demonstrated both clinically and by methods which estimate enzyme activity in small intestinal mucosa. The unhydrolysed and therefore predominantly unabsorbed disaccharide gives rise to diarrhoea, the stools being fluid, of an acid $p \mathrm{H}$ with a raised lactic acid and reducing sugar content. However, two groups of workers, Laplane, Polonovski, Etienne, Debray, Lods, and Pissarro (1962) and Lindquist and Meeuwisse (1962) have described infants in whom similar diarrhoea occurred when feedings were first instituted after birth, but in whom hydrolysis of the disaccharides appeared normal. These infants apparently could not absorb glucose or galactose, their diarrhoea ceasing only when feedings contained fructose as the source of sugar. The condition was also familial (Lindquist, Meeuwisse, and Melin, 1962).

This paper records a further family in which one infant was similarly affected and a sib was probably affected. The absorption of a number of disaccharides and monosaccharides was investigated and the results are discussed in relation to the mechanisms of sugar absorption.

\section{Case Report}

Elizabeth, the second child of healthy young unrelated parents was born in November 1961, in a country town, following a pregnancy during which her mother was well except for mild glycosuria in the later months. The confinement was normal. Breast feeding was established, but on the third day of life the baby developed severe watery diarrhoea which continued despite the feeding being changed to a sweetened condensed milk formula.

The mother's first pregnancy had resulted in a male baby who developed similar diarrhoea at 3 days of age. This diarrhoea had persisted for the whole 3 months of the baby's life and despite numerous investigations and

* In receipt of a grant from the National Health and Medical Research Council of Australia. feeding changes no cause was found and the baby died in a state of inanition and chronic dehydration. A necropsy did not reveal any abnormal findings except the poor nutritional state. When the second infant developed identical symptoms the general practitioner, suspecting a metabolic cause, referred her to our centre.

On admission, the baby, now 7 days of age, was moderately dehydrated, and still passing very numerous fluid stools which were acid and accompanied by much flatus. She required intravenous resuscitation. Diarrhoea ceased when oral fluids were withheld, but recurred on giving a glucose and electrolyte mixture orally, though the significance of this was not grasped at the time. In view of the other sib's illness and the type of stools, lactase deficiency was suspected and as the infant was again becoming dehydrated the feeding was changed to a lactose-free formula 'Sobee' before further investigation was pursued. The diarrhoea abated a little but by no means ceased. However, hydration was maintained though the weight was stationary.

No pathogenic organisms were found in the stool. A 24-hour stool collection contained $4.8 \mathrm{~g}$. fat and 850 $\mathrm{mg}$. lactic acid. Per-oral suction biopsy of the duodenal mucosa was performed and disaccharidase enzyme activity tested by a previously published method (Anderson, Messer, Townley, and Freeman, 1963). To our surprise lactose was well hydrolysed by the intestinal mucosa as was sucrose and maltose. The histological appearance of the mucosa was also normal.

At this critical stage a colleague directed our attention to a letter in a recent issue of the Lancet, by Lindquist et al. (1962) in which was described an infant with a similar clinical history in whom they had also suspected lactase deficiency only to find this was not the diagnosis. The baby thrived only when it was given an artificially contrived feeding in which the source of sugar was fructose. We immediately placed our patient on this type of feeding and diarrhoea ceased within 24 hours. The baby began to gain weight at a relatively normal rate. Her progress has been followed for 18 months. She is starting to walk and talk, and is alert, cheerful, and seems of normal intellectual and physical development.

The fluid feedings have been a mixture containing sodium caseinate, fructose, butter fat, and water, mixed together in a vitamizer into a coarse emulsion. Until about 8 months of age the concentration of the various 
constituents was as follows: sodium caseinate $3.5 \%$, butter fat $4 \%$, fructose $7 \cdot 5 \%$. Electrolytes were added to bring the sodium, potassium, and chloride content close to that of cows' milk. Calcium gluconate $1 \mathrm{~g}$., in divided doses, was given each day to the child, and in the early months vitamins $\mathrm{C}, \mathrm{K}, \mathrm{B} 12$, and folic acid, were added to the normal amount of a multivitamin preparation.

Several attempts were made to change the feeding back to cows' milk. On each occasion diarrhoea occurred, and if three such feedings, at intervals of three hours, were given the weight loss could amount to $0.4 \mathrm{~kg}$. The stools would become fluid and contain sugar and lactic acid in excess of normal.

At 6 months of age solid foods were introduced into the diet, these being at first confined to fruits (such as stewed apple, peach, or apricot), meat broth, and egg custard. Fructose was used as a sweetening agent and the artificial milk mixture to make the custard. Feeding these solids did not affect the stools, which at this stage consisted of one or two brown pasty bowel actions per day. After a few months a small amount of cereal was introduced and the mother learned by experience how much could be tolerated without causing the stools to become loose. At this stage the fructose content of the liquid feeding was decreased to $3.5 \%$.

Now, at the age of 18 months, the child is taking meat, vegetables, fruit, eggs, a small amount of cereal, a little ice-cream, custard made from special milk mixture, all without effect on the stools. Honey is tolerated fairly well and is now being used as a sweetening agent in other foods instead of fructose. A small amount of cows' milk was introduced at 18 months of age and though the child did not like it she could take up to 4 ounces each day before the stools became very loose.

\section{Special Investigations}

Once the patient was gaining weight following treatment with a glucose and galactose free diet, her tolerance to a number of sugars was tested. These included the monosaccharides, glucose, galactose, fructose, sorbose, mannose, xylose, and 3-0-methyl glucose, and the disaccharides lactose, sucrose, and maltose. Fructose and sorbose were obtained from Pfansteil Chemicals Inc., Waukegan, U.S.A., and 3-0-methyl glucose from L. Light and Son, England, and as a gift from Dr. R. K. Crane of Chicago. The remainder were from British Drug Houses. With the exception of $\mathrm{L}(+)$ sorbose all monosaccharides were in the $D(+)$ form.

A $10 \%$ aqueous solution of the sugar $(1.5 \mathrm{~g} . / \mathrm{kg}$. body weight, except for 3-0-methyl glucose) was given by gavage after a preliminary fast of 4-5 hours. Blood samples were obtained at half-hourly intervals for 2 hours and levels of blood sugar were determined by the method of Nelson (1944) and Somogyi (1952).

While the patient was nursed on a metabolic bed, stools and urine were collected separately for at least 6 and sometimes 24 hours following each dose. Previous experience in other cases of sugar intolerance had shown that, after a single dose of the offending sugar, the passage of sugar in the stool was rapid and largely completed in 6 hours. Therefore inconvenience to the patient during the numerous tolerance tests was cut down by collecting for only 6 hours. Both stools and urine were deep frozen soon after any was passed and were kept so until estimations for sugar or lactic acid were carried out.

The faecal samples were thawed, their volume was measured, and then they were homogenized, the volume being made up to 1 litre with tap water. An aliquot was centrifuged and $50 \mathrm{ml}$. of the supernatant deproteinized with the zinc sulphate, barium hydroxide reagents of Somogyi (1945). If necessary the stools were decolorized with activated charcoal, but this step was avoided if chromatography showed that disaccharides were present. The solution was then centrifuged and the supernatant analysed for sugar and lactic acid content.

For total reducing substance the Nelson (1944) and Somogyi (1952) method was used; for glucose, the glucose oxidase method of Huggett and Nixon (1957) as modified by Dahlqvist (1961); for 3-0-methyl glucose, the anthrone method, and for lactic acid the method of Barker and Summerson (1941).

The type of reducing sugar found in the stools was determined by paper chromatography: $2 \mu \mathrm{l}$. of the solution was spotted on to Whatman No. 1 chromatography paper; descending chromatography was used and the solvent, ethyl acetate, pyridine, water $(12: 5: 4)$, was allowed to drip from the end of a $30 \mathrm{~cm}$. length of paper. An overnight run was sufficient to separate the sugars tested with the exception of sorbose, mannose, and fructose. Where it was necessary to resolve these sugars, phenol water (160 g. phenol plus $40 \mathrm{~g}$. water) was used as the solvent. The spots were located by the silver nitrate reagent of Smith (1958).

The urine, after decolorization with activated charcoal, was also analysed by the above methods: $2 \mu$ l. of undiluted urine was used for urine chromatography.

The xylose absorption test was carried out by a method similar to that described by Clark (1962). The patient was fasted for 6 hours, then given a dose of xylose by gavage at the rate of $15 \mathrm{~g} . / \mathrm{m}^{2}$ of body surface area, as a $5 \%$ solution. Three doses of water each of $100 \mathrm{ml}$. were given at hourly intervals to encourage urine flow. Stools were collected for 6 hours and urine for 5 hours. Xylose was determined in all instances by the method of Roe and Rice (1948).

\section{Results}

Table 1 illustrates the patient's response to cows' milk feedings. After three feedings of cows' milk with added lactose, instead of her special feedings, the stools became fluid, their volume increased, as did their reducing substance and lactic acid content, the former in excess of the latter. She lost $0.4 \mathrm{~kg}$. body weight. Reducing substance equivalent to a considerable percentage of the administered sugar was found in the stool but it was shown by chromatography to be glucose and galactose, not lactose. The lactic acid content of the stool did not increase significantly until considerable amounts of sugar had 
already appeared in the stool indicating the diarrhoea to be 'osmotic' in origin.

Table 2 indicates the fate of the sugars which were given in individual test doses by recording the output of sugar and lactic acid in the stools, together with the maximum rise in blood reducing substances during two hours following the dose of sugar. Neither glucose nor galactose produced any rise in blood reducing substance and much of the sugar appeared in the subsequent stools, which were liquid. However, following a fructose dose no sugar appeared in the stool, the consistency of which was normal. The blood reducing substance rose slowly as is usual following fructose, normally a slowly absorbed monosaccharide.

The disaccharides lactose and maltose also showed little evidence of absorption. However, the sucrose dose was followed by some rise in blood reducing substance and less sugar in the faeces than followed the dose of lactose or maltose. After feeding a mixture of glucose and fructose very similar amounts of stool sugar were found. The feeding of sucrose was followed by a considerable rise in stool lactic acid-more than with any of the other sugars. A similar result was obtained on a second occasion.

Table 3 records the amount of sugar found in the stools and urine during 6 hours following a dose of the sugars mannose and sorbose. In each case the result obtained in a child of approximately the same age is recorded. Mannose, normally a poorly absorbed sugar, appeared in considerable quantity in the stool, with only a trace in the urine in both children. L-sorbose, a keto sugar, as is fructose, was
TABLE 1

STOOL ANALYSIS DURING AND AFTER 3 FEEDINGS OF COWS' MILK GIVEN AT 3-HOURLY INTERVALS

\begin{tabular}{c|c|c|c|c}
\hline $\begin{array}{c}\text { Hours } \\
\text { After } \\
\text { Initial } \\
\text { Feed }\end{array}$ & $\begin{array}{c}\text { Stool } \\
\text { Volume } \\
\text { (ml.) }\end{array}$ & $\begin{array}{c}\text { Total } \\
\text { 'Sugar' } \\
\text { (g.) }\end{array}$ & $\begin{array}{c}\text { Lactic } \\
\text { Acid } \\
\text { (mg.) }\end{array}$ & Fat (g.) \\
\hline 1 & 35 & 0.012 & 8 & $0 \cdot 5$ \\
5 & 240 & 3.9 & 143 & 1.6 \\
10 & 245 & $4 \cdot 2$ & 494 & 1.7 \\
24 & 130 & 0.5 & 154 & $2 \cdot 6$ \\
\hline Total & 650 & $8 \cdot 6$ & 799 & $6 \cdot 4$ \\
\hline
\end{tabular}

moderately well absorbed by both patient and 'control', a small quantity of the dose appearing in the stools which did become more fluid, but some also appearing in the urine. The metabolism of absorbed sorbose in the body is not clearly known, but it seems that our patient was able to absorb this sugar in approximately the same way as another child who had no disturbance of sugar absorption.

During the xylose tolerance test $10.5 \%$ of the dose of $5 \cdot 1 \mathrm{~g}$. was recovered from the urine. This result is at the lower end of the normal range quoted by Clark (1962). The mean absorption of 40 normal subjects tested by him was $24 \%$.

In Table 4 the absorption of 3-0-methyl glucose by the patient is compared with that of three other children. The latter, two of whom suffered from fibrocystic disease of the pancreas, a disease in which sugar absorption is not usually disturbed, and one normal child, absorbed this sugar well, since it was almost quantitatively excreted in the urine. The

TABLE 2

'SUGAR' AND LACTIC ACID IN STOOLS COLLECTED FOR 6 HOURS AFTER DOSE OF INDIVIDUAL SUGARS, AND MAXIMUM RISE OF BLOOD 'SUGAR' DURING 2 HOURS

\begin{tabular}{|c|c|c|c|c|c|}
\hline \multicolumn{2}{|c|}{ Sugar Fed } & \multicolumn{2}{|c|}{ 'Sugar' in Stool } & \multirow{2}{*}{$\begin{array}{l}\text { Stool } \\
\text { Lactic Acid } \\
\text { (mg.) }\end{array}$} & \multirow{2}{*}{$\begin{array}{c}\text { Blood 'Sugar' } \\
\text { Rise } \\
\text { (mg./100 ml.) }\end{array}$} \\
\hline Type & Amount (g.) & Type & Amount (g.) & & \\
\hline $\begin{array}{c}\text { Glucose } \\
\text { Galactose } \\
\text { Fructose } \\
\text { Maltose } \\
\text { Lactose } \\
\text { Sucrose } \\
\text { Fructose and glucose }\end{array}$ & $\begin{array}{c}7 \cdot 0 \\
7 \cdot 0 \\
7 \cdot 0 \\
7 \cdot 3 \\
7 \cdot 0 \\
7 \cdot 0 \\
3 \cdot 5 \text { and } 3 \cdot 5\end{array}$ & $\begin{array}{c}\text { Glucose } \\
\text { Galactose } \\
\text { Glucose } \\
\text { Glucose and galactose } \\
\text { Glucose }(1 \cdot 3 \mathrm{g.}) \\
\text { Glucose }(1 \cdot 3 \mathrm{g.})\end{array}$ & $\begin{array}{l}4 \cdot 1 \\
2 \cdot 56 \\
0 \cdot 03 \\
3 \cdot 9 \\
3 \cdot 9 \\
1 \cdot 5 \\
1 \cdot 4\end{array}$ & $\begin{array}{r}42 \\
26 \\
5 \\
54 \\
150 \\
320 \\
11\end{array}$ & $\begin{array}{l}10 \\
14 \\
18 \\
10 \\
17 \\
31 \\
11\end{array}$ \\
\hline
\end{tabular}

TABLE 3

'SUGAR' IN STOOLS AND URINE COLLECTED FOR 6 HOURS AFTER DOSE OF MANNOSE AND SORBOSE, COMPARED IN EACH CASE WITH ANOTHER CHILD OF APPROXIMATELY THE SAME AGE

\begin{tabular}{|c|c|c|c|c|c|}
\hline & Sugar Fed & Amount (g.) & Stool Volume (ml.) & Stool 'Sugar' (g.) & Urine 'Sugar' (g.) \\
\hline $\left.\begin{array}{l}\text { Patient } \\
\text { Control }\end{array}\right\}$ & Mannose & $\begin{array}{l}7 \cdot 0 \\
9 \cdot 3\end{array}$ & $\begin{array}{l}120 \\
385\end{array}$ & $\begin{array}{l}3 \cdot 14 \\
3 \cdot 5\end{array}$ & $\begin{array}{l}\text { No mannose } \\
\text { No mannose }\end{array}$ \\
\hline $\left.\begin{array}{l}\text { Patient } \\
\text { Control }\end{array}\right\}$ & Sorbose & $\begin{array}{r}13 \cdot 8 \\
7.9\end{array}$ & $\begin{array}{l}550 \\
560\end{array}$ & $\begin{array}{l}1 \cdot 6 \\
2 \cdot 44\end{array}$ & $\begin{array}{l}0 \cdot 825 \\
0 \cdot 316\end{array}$ \\
\hline
\end{tabular}


TABLE 4

'SUGAR' IN URINE AND STOOLS COLLECTED FOR 24 HOURS AFTER FEEDING 3-0-METHYL GLUCOSE TO PATIENT AND THREE OTHER CHILDREN

\begin{tabular}{|c|c|c|c|c|c|c|c|}
\hline & & \multirow{2}{*}{$\begin{array}{l}\text { Weight of } \\
\text { Child (kg.) }\end{array}$} & \multirow{2}{*}{ Dose (g.) } & \multicolumn{2}{|c|}{ Total 'Sugar' (g.) } & \multicolumn{2}{|c|}{ Glucose (g.) } \\
\hline & & & & Stool & Urine & Stool & Urine \\
\hline 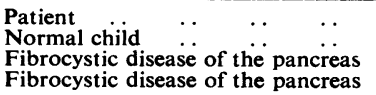 & \begin{tabular}{l|}
$\cdots$ \\
$\cdots$ \\
$\cdots$
\end{tabular} & $\begin{array}{r}11 \cdot 5 \\
9 \\
7 \cdot 5 \\
11 \cdot 5\end{array}$ & $\begin{array}{l}5 \\
5 \\
5 \\
17 \cdot 5\end{array}$ & $\begin{array}{l}0.957 \\
0 \cdot 025 \\
0 \cdot 437 \\
0.595\end{array}$ & $\begin{array}{l}0 \cdot 772 \\
5 \cdot 36 \\
3 \cdot 5 \\
16 \cdot 2\end{array}$ & $\begin{array}{l}0 \cdot 013 \\
0 \cdot 009 \\
0 \cdot 010 \\
0 \cdot 067\end{array}$ & $\begin{array}{l}0 \cdot 117 \\
0 \cdot 012 \\
0 \cdot 011 \\
0 \cdot 692\end{array}$ \\
\hline
\end{tabular}

stools were unaltered in consistency. However, the patient's absorption was grossly impaired, and during 24 hours a significant portion of the dose appeared in the stools which became liquid during the test period. A small quantity did appear in the urine together with a little glucose.

Random urine samples from the patient when she was taking cows' milk feedings always showed the presence of some glucose $(90-145 \mathrm{mg} . / 100 \mathrm{ml}$.). In normal babies of the same age and on similar feedings our experience has shown the level to be less than $30 \mathrm{mg} . / 100 \mathrm{ml}$. As the patient's blood sugar was seldom above $100 \mathrm{mg} . / 100 \mathrm{ml}$. intravenous glucose was given in an effort to raise the blood sugar to normal post-prandial levels. The glucose content of the urine increased when the blood sugar was between 100 and $160 \mathrm{mg} . / 100 \mathrm{ml}$, indicating a probable lowering of renal threshold for glucose.

\section{Discussion}

The clinical symptoms and results of investigations of this patient closely resemble those of the patients reported by Laplane et al. (1962) and Lindquist and Meeuwisse (1962), in that when the monosaccharides glucose and galactose and the disaccharides which contain these sugars (lactose, maltose, and sucrose) are fed, diarrhoea quickly develops. This leads to rapid loss of weight, dehydration, and electrolyte depletion, if the offending sugars are not removed from the diet. The stools become watery, acidic, and have a high sugar and lactic acid content. The diarrhoea may be severe enough to cause death in infancy. It seems likely that in the family we have studied another baby died of the condition. There were a number of deaths in infancy from chronic diarrhoea in the families of the patients described by Lindquist, Meeuwisse, and Melin (1963).

In contrast, the monosaccharide, fructose, is well absorbed by these patients, and when an artificial feeding containing this sugar together with a source of protein (casein) and fat (butter or corn oil) is fed they thrive and diarrhoea does not occur.

At the time when our patient presented for investigation only the brief report in a letter to the
Lancet by Lindquist et al. (1962) from Northern Sweden was available to us, but subsequently we found the independent, but slightly earlier, description of two other such babies by Laplane et al. (1962) from France who had carried out their investigations along very similar lines and had come to virtually the same conclusions regarding the possible absorptive defect as did Lindquist and co-workers. To our knowledge the reports from these two groups of workers and ourselves are, as yet, the only recorded descriptions of this condition. It is interesting to note the similarity in methods of investigation and findings among three independent groups of workers at about the same time in three widely separated countries.

Regarding their absorption and transport across intestinal epithelial cells, monosaccharides are divided into two groups, i.e. those 'actively' absorbed against a concentration difference, and those 'passively' absorbed by a diffusion process (Wilson, 1962). It appears that the sugars belonging to the 'actively' absorbed group, such as glucose and galactose, are those affected in these patients, whereas fructose, of the 'passively' absorbed group, is dealt with normally.

In all patients described sucrose was better tolerated than other disaccharides, presumably because half the molecule is fructose. In support of this was the response obtained when we fed a mixture of glucose and fructose in equimolar amounts to our patient. Almost identical amounts of sugar appeared in the stools as with the equivalent dose of sucrose.

After feeding any of the disaccharides, stool chromatography showed only the constituent monosaccharides. Miller and Crane (1961) have demonstrated that the disaccharidase enzymes are located in the brush border of the intestinal epithelium and are not secreted into the lumen. In children with specific disaccharidase deficiencies, e.g. lactase or sucrase deficiencies, some of the particular disaccharide is found unsplit in the faeces (Auricchio, Dahlqvist, Mürset, and Prader, 1962; Auricchio, Rubino, Landolt, Semenza, and Prader, 1963). Therefore, in these monosaccharide intolerant 
patients, it seems that the disaccharides must be absorbed into or onto the brush border, hydrolysed, then the glucose and galactose passed back into the lumen. Crane (1962) believes that there are two regions in the brush border: the outer, where the disaccharidases are situated, and the inner, where the so-called active sodium-dependent transport of monosaccharides into the epithelial cell itself takes place. The handling of disaccharides by these patients supports this view.

The precise mechanism of active transport is as yet unknown but it is accepted to be sodium dependent, and related to the 'sodium pump'. It is also said to be 'carrier-mediated', but the carrier is unknown. Wilson (1962) summarizes the evidence so far available. There was no indication cf any other disturbance of the 'sodium pump' mechanism in our patient. However, there was some evidence that glucose resorption in the kidney tubules was impaired and Lindquist and Meeuwisse (1962) have also suggested this but without very definite evidence. It has been suggested by workers studying Hartnup's disease, in which there is a disturbance of amino acid absorption in both the gut and the kidney tubule, that the normal mechanism of absorption may be the same in both situations. It is possible that the mechanism for glucose absorption is also the same in both situations.

Wilson (1962) when reviewing experimental work with animals regarding the specificity of the 'active' transport mechanism points out that the presence of a hydroxyl group on carbon atom 2 of the monosaccharide molecule is an essential feature. 3-0methyl glucose, a synthetic sugar with this basic configuration, was shown by Csaky (1942) to have a similar rate of absorption to glucose but it is not metabolized, being rapidly passed out in the urine. This sugar was very poorly absorbed by our patient in comparison with other children, indicating again that the 'active' absorption mechanism is defective. The small amount that did appear in the urine may represent some passive diffusion of the sugar, which, as it is not metabolized, rapidly appears in the urine.

Mannose and xylose have been included among the sugars that are not actively absorbed. However, mannose is extremely poorly absorbed by humans and in our patient the response to a dose did not differ from that we obtained in normal children. Xylose was absorbed by our patient to about $50 \%$ of the mean normal absorption quoted by Clark (1962). However, recent work by Salomon, Allums, and Smith (1961) throws doubt on the acceptance of xylose as a purely passively absorbed sugar, indicating it may have some affinity for the glucose carrier.

The absorption of sorbose was tested because this is a 'keto' sugar which may have a furanose ring structure like fructose, while glucose and galactose are 'aldo' sugars with a pyranose ring structure. The latter is also said to be a characteristic of 'actively' absorbed sugars. We found the $\mathrm{L}$ form of sorbose (the D form was unavailable) to be slowly absorbed by normal children, and to be not completely metabolized as it appeared in the urine in significant quantity. Our patient absorbed L sorbose in a similar fashion to normal children.

Thus all data from the tests on absorption of sugars in our patient support the concept that the 'actively' absorbed sugars are not transported into or across the intestinal epithelial cell in a normal fashion, whereas the 'passively' absorbed sugars are. It seems that patients such as this might offer opportunities to study the 'active absorption' mechanism, to try to throw more light on the relation of the sodium pump and the identity of the 'mobile carrier system' postulated by Crane (1962).

Clinical management of these patients is largely confined to manipulation of the diet which has been described in some detail in this paper. As the child grows some carbohydrate containing the involved monosaccharides can be tolerated in the diet, but only trial and error will determine how much. As we believe that the diarrhoea caused by unabsorbed sugar is largely 'osmotic' in origin, the severity of the diarrhoea will depend on the concentration of unabsorbed sugar in the gut at any time. Diarrhoea or looseness of the stools can be kept to tolerable levels if the total intake of the offending carbohydrates is low and distributed throughout the daily meals. A personal communication from B. Lindquist and G. Meeuwisse (1964) revealed that one of their patients, a 36-year-old woman who had been discovered because she was a relative of a previously diagnosed patient, had been able to manipulate her own diet to avoid a carbohydrate or milk intake that caused troublesome diarrhoea. She was thin but healthy.

The condition appears to be familial and Lindquist et al. (1963) describe 4 proven cases in Northern Sweden, 3 of whom are related. In the families of these 3, which can be traced to a common ancestor, there were 6 deaths in infancy from chronic diarrhoea. They suggest that the pedigrees demonstrate an autosomal recessive type of inheritance of the disease. These patients therefore display yet another inborn error of metabolism, one in which the development of the 'active' transport mechanism of monosaccharides across epithelial cells is defective.

Summary

A patient with symptoms closely resembling those 
of disaccharide intolerance but in whom there was defective intestinal absorption of certain monosaccharides is described.

The monosaccharides affected were those described as absorbed 'actively' against a concentration difference, and included glucose, galactose, and 3-0-methyl glucose.

Disaccharides containing any of these monosaccharides also caused similar symptoms.

The passively absorbed sugar fructose was handled normally, and comprised the chief carbohydrate content of the child's diet.

Only two other reports of such patients are available, but the condition is familial and probably represents another inborn error of carbohydrate metabolism.

We are grateful to Mrs. Stebbing and to Miss Milroy for technical assistance; to the Infant Formula Room and Dietary Department for considerable help in constructing special diets; to the nursing staff who watched over the numerous metabolic collections; and to Dr. R. K. Crane who kindly gave us some 3-0-methyl glucose.

\section{REFERENCES}

Anderson, C. M., Messer, M., Townley, R. R. W., and Freeman, M. (1963). Intestinal sucrase and isomaltase deficiency in two siblings. Pediatrics, 31, 1003.

Auricchio, S., Dahlqvist, A., Mürset, G., and Prader, A. (1962). Intestinal isomaltose deficiency in patients with hereditary sucrose and starch intolerance. Lancet, 1, 1303.

-, Rubino, A., Landolt, M., Semenza, G., and Prader, A. (1963). Isolated intestinal lactase deficiency in the adult. ibid., $2,324$.
Barker, S. B., and Summerson, W. H. (1941). The colorimetric determination of lactic acid in biological material. J. biol. Chem., 138, 535.

Clark, P. A. (1962). The use of the d-xylose excretion test in children. Gut, 3, 333 .

Crane, R. K. (1962). Hypothesis for mechanism of intestinal active transport of sugars. Fed. Proc., 21, 891.

Csaky, T. (1942). Über die Rolle der Strucktur des Glucosemoleküls bei der Resorption aus dem Dünndarm. Hoppe-Seylers $Z$. physiol. Chem., 277, 47.

Dahlqvist, A. (1961). Determination of maltase and isomaltase activities with a glucose-oxidase reagent. Biochem. J., 80, 547.

Huggett, A. St. G., and Nixon, D. A. (1957). Use of glucose oxidase peroxidase, and $\mathrm{O}$-dianisidine in determination of blood and urinary glucose. Lancet, 2, 368.

Laplane, R., Polonovski, C., Etienne, M., Debray, P., Lods, J. C., and Pissarro, B. (1962). L'intolérance aux sucres a transfert intestinal actif. (Ses rapports avec l'intolérance au lactose et le syndrome coeliaque.) Arch. frans. Pédiat., 19, 895.

Lindquist, B., and Meeuwisse, G. W. (1962). Chronic diarrhoea caused by monosaccharide malabsorption. Acta paediat. (Uppsala), 51, 674.

$\longrightarrow,-$, and Melin, K. (1962). Glucose-galactose malabsorption. Lancet, 2, 666.

(1963). Osmotic diarrhoea in genetically transmitted glucose-galactose malabsorption. Proc. Swedish Paediatric Soc. Acta paediat. (Uppsala), 52, 217.

Miller, D., and Crane, R. K. (1961). The digestive function of the epithelium of the small intestine. II. Localization of disaccharide hydrolysis in the isolated brush border portion of intestinal epithelial cells. Biochim. biophys. Acta (Amst.), 52, 293.

Nelson, N. (1944). A photometric adaptation of Somogyi method for the determination of glucose. J. biol. Chem., 153, 375 .

Roe, J. H., and Rice, E. W. (1948). A photometric method for the determination of free pentoses in animal tissues. ibid., 173, 507.

Salomon, L. L., Allums, J. A., and Smith, D. E. (1961). Possible carrier mechanism for the intestinal transport of d-xylose. Biochem. biophys. Res. Commun., 4, 123.

Somogyi, M. (1945). Determination of blood sugar. J. biol. Chem., $160,69$.

(1952). Notes on sugar determination. ibid., 195, 19.

Smith, I. (1958). Chromatographic Techniques. Heinemann, London. Wilson, T. H. (1962). Intestinal Absorption. W. B. Saunders, Philadelphia. 